\title{
En los límites de la frontera oeste: etnografía histórica de los puestos indígenas del SPI en Mato Grosso (Brasil)
}

Aceptación: Marzo - 2008

Aprobación: Junio - 2008

Lucybeth Camargo de Arruda*

\section{RESUMEN}

El SPI - "Serviço de Proteção aos Índios", creado para operar junto a los indígenas en Brasil- fue fundamental para mediar en los conflictos existentes entre grupos indígenas y no indígenas y, de esa forma, permitir el poblamiento colonizador al inicio del siglo XX, a partir de 1910. En tal contexto histórico-social, el objetivo del presente artículo es esbozar una etnografía histórica de los frentes de contacto del SPI y de los frentes de expansión con los pueblos indígenas en el Estado de Mato Grosso, frontera oeste, con enfasis en las relaciones producidas: conflictos y enfrentamientos generados, dinámicas de movimiento territorial, negociaciones, retrocesos y aproximaciones.

PALABRAS CLAVE: puestos indígenas, frentes de contacto, frentes de expansión, Mato Grosso (Brasil)

\section{ABSTRACT}

The "SPI" (Indian Protection Service) was set up at the beginning of the 20 $20^{\text {th }}$ century to support the Brazilian Indians in solving conflicts between the Indian and non Indian groups, and so doing, to allow the colonizer settlement since 1910. In such social-historical context, the aim of this article is to sketch an historical ethnography of the SPI contact fronts and the expansion fronts of the indigenous people in the West frontier, i. e., Mato Grosso state. The article focuses on the relations, conflicts, dynamics of the territorial movements, negotiations, draw backs and rapprochements between Indian and no Indian groups.

KEY WORDS: indigenous reductions, contact fronts, expansion fronts, Mato Grosso (Brazil). 
La frontera oeste de Brasil, que abarca todo el territorio de Mato Grosso y parte de la región norte, fue descubierta en el siglo XVIII, durante el proceso de búsqueda por conquista territorial, explotación de oro y captura de indios. A pesar de la incursión de la Corona portuguesa, que llegó hasta el margen izquierdo del río Guaporé, estos límites solo ganaron fuerza con el avance de los frentes de expansión al inicio del siglo $X X$, con una política de reasentamiento para los indios y otra de incentivo a la expansión territorial y comercial de los colonizadores. Esta delimitación espacial -frontera oeste- era denominada sertão (región agreste), explicitando una visión de lugar hostil, habitado por indios "salvajes" y que necesitaba de una embestida por parte del gobierno brasilero con la finalidad de ser integrada, conjuntamente con estos grupos indígenas, a los moldes de civilidad de la nación en proceso de consolidación. El Servicio de Protección a los Indios y Localización de Trabajadores $\mathrm{Na}$ cionales (SPILTN), creado para gestionar políticas indigenistas, fue fundamental para mediar los conflictos existentes entre indígenas y no indígenas y así permitir el poblamiento colonizador. En este contexto histórico-social me interesa realizar una etnografía sobre la creación de los puestos indígenas, los frentes de contacto del SPI con los pueblos indígenas, prestando atención a las relaciones producidas a partir de ese contacto y de la delimitación del espacio para la instalación de los puestos de pacificación. El problema a indagar es el siguiente: ¿cuáles son los conflictos y enfrentamientos generados, el movimiento territorial, las negociaciones, los retrocesos y las aproximaciones de los agentes del SPI y de los frentes expansivos (hacendados, pequeños agricultores, caucheros, buscadores de metales y piedras preciosas, entre otras categorías sociales) con los pueblos indígenas de esa región?

El recorte temporal de este trabajo es del siglo XX, específicamente a partir de 1910, año de la creación del Servicio de Protección a los Indios y Localización de los Trabajadores Nacionales (SPILTN), en el espacio que hoy corresponde al Estado de Mato Grosso, en el centro-oeste de Brasil, extendiendo el análisis hasta la década de 1950. En ese período, la apertura de las regiones y la redefinición territorial formaban parte de un programa nacional que apuntaba a consolidar Brasil como un Estado soberano.

Povoamento, ocupação, integração constituem os novos movimentos da Nação em busca de sua plenitude. (...) O espaço físico unificado constitui o lastro empírico sobre o qual os outros elementos constitutivos da Nação se apóiam: a unidade étnico-cultural, a unidade econômica, política, o sentimento de ser brasileiro (Lenharo, 1986:57)*.

El Servicio de Protección a los Indios y Localización de Trabajadores Nacionales (SPILTN) tuvo como principal objetivo intervenir en la frontera oeste, como consecuencia del proyecto más amplio de construcción de la nación, el cual tenía como metas no solo la "pacificación" de los indígenas "hostiles", como también le cabía dar: Assistência, ensino e providenciar de toda a natureza de modo a apressar sem nenhuma (sic) coação, a emancipação dos índios e sua digna incorporação na sociedade brasileira, saudáveis do corpo e capazes do trabalho livre ${ }^{1 * *}$.

El Estado centrado en la $1^{\text {a }}$ República, en el tiempo de Cándido Mariano Rondon², pre-

\footnotetext{
* “En búsqueda de plenitud, el poblamiento, la ocupación y la integración constituyen los nuevos movimientos de la nación (...) El espacio físico unificado constituye la base empírica sobre la cual los otros elementos constitutivos de la nación se apoyan: la unidad étnico-cultural, la unidad económica, política, y el sentimiento de ser brasilero".

1 Acta resumida de exposición sobre el Servicio de Protección a los Indios. Microfilme 380. Fotograma 886.

** "Asistencia, educación y providenciar de toda naturaleza de modo de apurar sin ninguna (sic) imposición, la emancipación de los indios y su digna incorporación en la sociedad brasilera, con cuerpos saludables y capaces de realizar un trabajo libre".

2 En palabras de Lima, "El SPI surgió como una creación personal y venerable de su primer director general, en la época teniente-coronel Cándido Mariano da Silva Rondon, momento en que raramente se frecuentaron las páginas de los estudios antropológicos. Cándido Rondon, paradigma moderno desbravador de las regiones, uno de los mitos incontestables de la historia oficial de Brasil republicano, es el patrono de armas de Comunicación del Ejército, de las Telecomunicaciones en nuestro país, y primer brasileño a ser presentado como candidato al Premio Nobel de la Paz, en 1958, objeto de innúmeras biografías encomiásticas".
} 
veía una auspiciosa planificación y estudio de los límites de Brasil, en especial de la frontera oeste, transformando los territorios indígenas en aldeas (espacios recortados y delimitados) y manteniendo a los indios bajo el poder tute$\operatorname{lar}^{3}$, según los moldes de la urbanidad requeridos por el proyecto civilizatorio, con (...) os índios nas suas casinholas de telha e até luz elétrica, as vacas leiteiras pastando no campestre aramado, limitado pelas águas dos rios Paraguai e Bugres ${ }^{4^{*}}$ (Cabral, 1963:281). El proyecto ideológico diseñado por Rondon colocaba en evidencia los intereses de la república emergente en relación a las etnias de Brasil y más aún, según Lylia Galletti, representaba la inserción efectiva del progreso, a través de la acción civilizadora sobre los grupos indígenas.

Ao mesmo tempo, a Comissão descortinava os sertões mato-grossenses como uma fronteira do país, na sua dupla acepção de espaço da barbárie e terras novas -região abundante em recursos naturais, que ela própria encarregava-se de inventariar- a ser colonizada pela nação (Galletti, 2000:234)".

Sin embargo, en el momento previo a la instauración de las políticas tutelares sobre los grupos indígenas y al proceso de disciplinamiento corporal direccionado hacia el trabajo rural, por medio de la intervención del SPILTN, como fue mencionado arriba, existieron otras acciones de intervención estatal, lo que ciertamente demuestra que las experiencias de control de las poblaciones indígenas se acumulaban y eran difundidas oficialmente a lo largo del proceso de contacto.

Cándido Mariano Rondon, antes de asumir la dirección del SPI, acumuló experiencia en la Comisión de Líneas Telegráficas, añadiendo, a partir de 1910, con la creación del SPI, dos funciones en el Gobierno Federal: la de director general de la Comisión Rondon o, mejor dicho, de la Comisión de Líneas Telegráficas y Estrategias de Mato Grosso al Amazonas; y también la de presidente del órgano tutelar de los indígenas, asumiendo la responsabilidad de localizar, pacificar y promover la civilización de los pueblos indígenas.

Esta doble actividad de Rondon permite afirmar que hubo una acción articulada entre las dos instituciones en la redefinición de los espacios geográficos de las regiones centro-oeste y norte de Brasil. Al hacerlo de esta manera, el sertanista contribuyó para la consolidación poblacional de las regiones, con la apertura de nuevos frentes de colonización, mercados regionales y sobre todo con la promoción de la distensión de los conflictos entre colonizadores y pueblos indígenas, reservando tierras para la especulación y expansión económica.

Por lo tanto, a partir de la localización y contacto en los territorios indígenas, el próximo paso fue la redefinición de estos espacios, con el establecimiento de fronteras y discursos cartográficos y la instalación de equipamientos y contingente para establecer las condiciones mínimas en función de la pretendida "reeducación".

En ningún momento la estrategia de conquista, pacificación y redefinición geográfica estuvo desconectada de un fuerte interés económico expansionista. En un documento, el SPI indica la eficacia de este órgano, que se presentó como una verdadera punta de lanza de los nuevos frentes de expansión:

A excelência e absoluta eficácia do processo usado pelo Serviço (SPI) para pacificar os sertões disputados por civilizados às tribos guerreiras que as ocupam desde épocas imemoriais, só lhes teríamos de responder

3 Según la definición de Antonio Carlos de Souza Lima en Um Grande Cerco de Paz (1995), el ejercicio del poder tutelar consiste en obtener el monopolio de los actos de definir y controlar, en cualquier ámbito, de la población en la que se incidirá.

4 Este fue el proyecto idealizado por Rondon en el Puesto Fraternidad Indígena para abrigar a los indios de la etnia Umutina, a partir de la fundación del puesto en el año 1913.

* "los indígenas en sus pequeñas casas de teja y con luz eléctrica, las vacas lecheras pastando en el campestre cercado, limitado por las aguas de los ríos Paraguay y Bugres".

** "Al mismo tiempo, la comisión develaba las zonas agrestes mato-grossenses como una frontera del país, en su doble aceptación de espacio de barbarie y tierras nuevas - región abundante en recursos naturales, que ella misma se encargaba de inventariar - al ser colonizada por la nación". 
que esse processo já havia dado idênticos resultados ao General Gomes Carneiro, o empregou em 1891 aos índios Bororos do rio das Garças, que impediam a passagem da linha telegráfica de Goiás para Cuiabá; aos Nambikuaras, que defendiam as florestas abundantes de seringueira da região do Juruena; aos Barbados, que desde tempos coloniais fechavam ao acesso dos civilizados às matas da Poaia; aos Arikunes e a dez outras nações de índios guerreiros que habitam o vasto Noroeste Mato-Grossense a partir do Planalto dos Parecis até as margens do Madeira ${ }^{5 *}$.

Los frentes de expansión, abocados a la explotación extractiva vegetal y mineral y, concomitantemente, a la fundación de ciudades y áreas rurales, fueron adentrándose en los territorios indígenas como si fuese tierra de nadie o sencillamente amparándose en el cuño del Estado brasilero, que hacía la concesión con el propósito de la colonización, restando para los grupos indígenas la reducción en los puestos de atracción, montados por los agentes del SPI.

En la documentación revisada hasta la fecha fueron identificadas, entre las décadas de 1910 y 1940, tres listas que contienen los nombres de los puestos localizados en Mato Grosso, considerando que ya en 1925 un informe de la Inspectoría Regional 06 apuntaba 18 puestos y una población indígena:

Utiarity, no Rio Papagaio - Juruena; Paca Novas - Rio Mamoré; Rolim de Moura Sararé - Alto Guaporé; Três de Maio - Rio São Miguel - Baixo Guaporé; Pedro Dantas - Telles Pires - Tapajós; Fraternidade Indígena - Alto Paraguai; Simões Lopes - Paranatinga; Córrego
Grande - Rio São Lourenço; Jardore - Rio São Lourenço; Quedjare - Rio São Lourenço; Povoação Indígena de São Lourenço - Alto São Lourenço; Perigára - Baixo São Lourenço; Bananal (Estrada de Ferro Noroeste); Cachoeirinha (Estrada de Ferro Noroeste); Presidente Alves de Barros - Bodoquena - Cadiéus; Lalima - Estrada de Ferro Noroeste; Francisco Horta - Rio Dourados (Caiuás); Capitão Victurino - Brejão e Juina - Rio Juruena ${ }^{6}$

En otro documento de 1926, que relata los trabajos de la Inspectoría del SPI en Mato Grosso, el inspector interino, Antonio Martins Viana Estigarríbia, declaró la existencia de 17 establecimientos del SPI (puestos) y el control de numerosas aldeas (fuera de ellos) "que disponen de campos propios, estamos fundando centros de creación de bueyes, caballos, cabras etc." $"$

Ya en el año 1944, es posible verificar la existencia de diez puestos, entre los cuales seis fueron denominados Puesto de Atracción de Indios (PIA) y los otros cuatro denominados Puesto de Asistencia, Nacionalización y Educación (PIN).

La expansión colonizadora en la frontera oeste causó muchas transformaciones en las trayectorias históricas de los actores sociales involucrados, sobre todo de los pueblos indígenas que tuvieron que convivir en una nueva dinámica social, en una reconfiguración espacial y política, sufriendo acciones disciplinadoras por parte de los agentes del SPI en el intento de moldear la geografía con las instalaciones de los puestos de atracción y de adecuar los grupos indígenas a los padrones de la "civilización".

5 Documento del SPI - 1918. Microfilme 380. Fotograma 1225, Museo del Indio/FUNAI-RJ.

* $\quad$ "La excelencia y absoluta eficacia del proceso usado por el servicio (SPI) para pacificar los sertões disputados por civilizados a las tribus guerreras que ocupaban estos territorios desde épocas inmemoriales, solo les tendríamos que responder que esos procesos ya le habían dado resultados idénticos al General Gomes Carneiro, quien los empleó en 1891 con los indios Bororos del río de las Garzas, cuyos miembros impedían el paso de la línea telegráfica de Goiás hacia Cuiabá; con los Nambikuaras, que defendían los abundantes bosques de la región de Juruena; con los Barbados, que desde tiempos coloniales cerraban los accesos de los civilizados a los bosques de Poaia; con los Arikunes y con otras diez naciones de indios guerreros que habitan el vasto Noroeste Mato-Grossense a partir de la altiplanicie de los Parecis hasta los márgenes de Madeira".

6 Documento de publicación de la relación de los puestos y poblaciones mantenidos por el SPI en 1925. Microfilme 380, fotograma 822. Museo del Indio, Rio de Janeiro.

7 Informe del Inspector interino Antonio Estigarríbia a gobernador del Estado de Mato Grosso sobre las acciones del SPI en los puestos localizados en el estado. Documento de 31 de mayo de 1926, de la Inspectoría de Mato Grosso. Carpeta Ministerios - Archivo Público de Mato Grosso. 
De acuerdo con la noción de disciplinamiento, propuesta por Foucault, la localización en el espacio ocurre a través de su cuadriculación, permitiendo una especie de control cartográfico, pues pasa a:

Estabelecer as presenças e as ausências, saber onde e como encontrar os indivíduos, instaurar as comunicações úteis, interromper as outras, poder a cada instante vigiar o comportamento de cada um, apreciálo, sancioná-lo, medir as qualidades ou os méritos. Procedimento, portanto, para conhecer, dominar e utilizar. A disciplina organiza um espaço analítico* (Foucault, 1999: 123).

Vemos que, siguiendo el raciocinio de este autor, se crea la necesidad de civilizar a los grupos indígenas y el espacio en el que habitan, yendo más allá del objetivo de vigilar; se construye un lugar útil directamente ligado al trabajo, necesario para el proyecto civilizador de los gestos del indígena, que en la concepción social darwinista elevaba la moral, desarrollando las reglas de convivencia pautadas en la disciplina. Tales prácticas positivistas tuvo sus raíces en la militarización del órgano que administraba a los indígenas y también en otras instituciones del Estado, entre ellas: la escuela.

Con la intención de intensificar el abordaje antropológico, propongo entender los puestos indígenas insertos en un contexto social, político y cultural, conforme los parámetros teórico-metodológicos de una antropología procesual, permitiéndome un diálogo interdisciplinario con la historia. Aquí, por lo tanto, los objetivos son etnohistóricos, intentando llevar a cabo un ejercicio de tomar las fuentes históricas para observar los grupos indígenas dentro de esa coyuntura de la política expansionista, de cómo ellos fueron vistos, de cómo fueron tratados $y$, en el diálogo con esas fuentes, identificar los desvíos y reacciones de los grupos indígenas, entendiéndolos sobre todo como grupos étnicos, reconfigurando y resignificando su alteridad.

En los últimos años, la proximidad entre los campos (Antropología e Historia) viene siendo realizada con propiedad por investigadores tanto en el de la Historia como en el de la Antropología, trabajando con instrumentales prestados y en la frontera de los campos. Buscando esta proximidad, en esta investigación doy gran importancia a los trabajos que abordan la política indigenista del $\mathrm{SPI}^{8}$, como también a los estudios antropológicos que trabajan la cuestión de los asentamientos, aunque en otros tiempos históricos, como es el caso de las autoras María Regina Celestino de Almeida con su trabajo "Metamorfoses Indígenas", Marta Amoroso "Conquista do Paladar -Os Índios, o Império e as Promessas da Vida Eterna" e Izabel Missagia de Mattos "Civilização e Revolta- Os Botocudos e a Catequese na Província de Minas".

En este proceso sociocultural, el diálogo teórico considera la concepción de cultura, tal como es proyectada por E. P. Thompson, inserta en un contexto histórico que parte de las experiencias vividas por los grupos sociales que establecen sus relaciones, en este caso: las etnias, los agentes y trabajadores del SPI y los frentes de expansión y colonización. Otro aporte teórico importante es la obra de João Pacheco de Oliveira, quien también considera el tiempo histórico para entender las relaciones étnicas y de alteridad. Otro trabajo que está iluminando la presente discusión es la obra de María Regina Celestino, "Metamorfoses Indígenas", la cual trata sobre los poblamientos del siglo XVI, en Río de Janeiro, ofreciendo reflexiones importantes en el sentido de comprender que las estrategias del SPI no fueron inventadas en la $1^{\text {a }}$ República, sino solo reconfiguradas en base a las acciones de los tiempos y contextos coloniales en lo que respecta a la pacificación y también a la concepción de la relación con el otro, con raíces consolidadas en las teorías evolucionistas.

“Establecer las presencias y las ausencias, saber dónde y cómo encontrar los individuos, instaurar las relaciones útiles, interrumpir las otras, poder a cada instante vigilar el comportamiento de cada uno, considerarlo, sancionarlo, medir las cualidades o los méritos. Procedimiento, por tanto, para conocer, dominar y utilizar. La disciplina organiza un espacio analítico".

8 Utilizaré referencias tales como: Antonio Carlos de Souza Lima y su publicación "Um grande Cerco de paz: Poder Tutelar e Indianidade no Brasil” y, también, “O governo dos índios soba gestão do SPI”, en: Manuela Carneiro da Cunha (Org.) “História dos Indios no Brasil”; Darcy Ribeiro, en "A política indígenista brasileira” y consiguientemente el trabajo de João Pacheco de Oliveira Filho en "O nosso governo; os Ticuna e o regime tutelar". 
Un dato estimulante para este estudio se encuentra en la afirmación de João Pacheco de Oliveira, en su libro "Indigenismo e Territorialização", quien afirma que las áreas demarcadas en Mato Grosso, con datos levantados entre los años de 1972 y 1982, reflejan directamente la actividad de la Comisión Rondon, en los inicios del SPI. Según este autor, aunque el número de áreas demarcadas por el SPI es realmente elevado (54), la extensión total de esas tierras es de menos de 300 mil hectáreas, resultando una porción prácticamente insignificante $(2,4 \%)$ del total de tierras indígenas ya demarcadas hasta ese período. Este dato confirma la eficacia de la acción del SPI que estableció áreas reducidas para los grupos étnicos y consiguió asegurar las porciones de tierras para los frentes de expansión (Oliveira, 1998: 32 y 33).

Además de la cuestión territorial en aquel período, es importante reconocer la presencia de la Iglesia Católica en los puestos, a pesar de que, con la intervención del SPI, la "catequesis" fue abolida en su mayor parte. Sin embargo, en determinados momentos y circunstancias entró en escena la acción catequizadora, lo que nos permite insinuar que esta también estuvo articulada con el SPI al servicio de la ocupación, dependiendo de la situación, sobre todo en lo que se refiere a la resistencia de los grupos indígenas al proceso civilizador. Esta hipótesis puede ser verificada en el puesto de atracción y pacificación en el Valle del Guaporé con el grupo Nambikuara en cuyo seno la presencia colonizadora se dio con la extracción de la Jeringa y también con la presencia en la década de 1930 de la Compañía Jesuítica. Otra posibilidad que es interesante para verificar la relación del SPI con la Iglesia Católica es a través de un estudio de la etnia Xavante, sobre la cual verificamos relatos significativos acerca de la resistencia de los indígenas en relación a la propuesta de reducción y reeducación. En la documentación queda claro que la tan anhelada "pacificación" ocurrió a mediados de la década del 40 del siglo XX. En este caso se constata, en 1937, la presencia de la Misión Salesiana, que consiguió "um encontro amistoso com este gentio, que espontaneamente apareceu ao missionário aceitando e retribuindo presentes como prova de simpatia e amizade" $9^{*}$

El informe de la misión salesiana fue enviado para componer el proceso de subvención de la Misión entre los indios xavante. En la carta, el Director de la Misión Salesiana Hipollyto Chovelon, argumenta en favor de la misión diciendo que, el local en que los indios xavante estaban localizados, en la región de Río de las Muertes a más de 140 leguas de su límite con el río Araguaia, era una zona riquísima de campiñas y selvas, adecuadas para la realización de labranzas y crianza de ganado, pero no para servir a los indígenas que deseaban pacificar.

O povoamento depende tão só da pacificação dos índios Chavantes que até agora fazem o terror dos moradores das vizinhanças pelas suas correrias e ataques traiçoeiros. Daí decorrer a necessidade urgente de amparar a Missão Salesiana que já tem obtido um encontro amistoso, a fim de favorecer-lhe os meios de uma penetração mais eficaz, tendendo ao aldeamento e educação da tribo Chavante, abrindo assim esta imensa zona entre os Rios Xingu e Araguaia aos progressos de nossa civilização. É pois, obra eminentemente patriótica, e por isso não duvido que V. Excia., cujas vistas estão lançadas para este Oeste tão futuroso e de grandes reservas para o Brasil, saiba compreender o alcance desta avançada pacífica e conquistadora ${ }^{10^{*}}$

9 Carta de presentación, de febrero de 1938, dirigida al Presidente de la República Getulio Vargas, del informe de la Misión Salesiana entre los indios Chavantes del año de 1937. Documento de la carpeta Ministerios - Archivo Público de Mato Grosso.

* “(...) un encuentro amistoso con este gentío, que espontáneamente se presentó delante del misionero aceptando y redistribuyendo regalos como prueba de la simpatía y amistad"

10 Carta de presentación, de febrero de 1938, dirigida al Presidente de la República Getulio Vargas, del informe de la Misión Salesiana entre los indios Chavantes del año de 1937. Documento de la carpeta Ministerios - Archivo Público de Mato Grosso.

* "El poblamiento depende solamente de la pacificación de los indios Chavantes que hasta ahora son el terror de los habitantes de los alrededores por sus desórdenes y ataques traicioneros. Es por ese motivo que surge la necesidad urgente de amparar la Misión Salesiana que ya a realizado un encuentro, con el fin de facilitarle los medios para una incursión más eficaz, tendiendo a la conformación de aldeas y educación de la tribu Chavante, abriendo así esta inmensa zona entre los ríos Xingu y Araguaia a los progresos de nuestra civilización. Es pues, una obra eminentemente patriótica, y por eso no tengo dudas que V. Excelencia., cuyas intenciones están apuntadas para este Oeste con tanto futuro y de grandes reservas para Brasil, sepa comprender el alcance de esta avanzada pacífica y conquistadora". 
Varios factores fueron considerados para evitar las provocaciones entre las sociedades indígenas y no indígenas en las expediciones de la región. Uno de estos factores fue la "nueva" delimitación de las tierras propuestas, la cual, de forma genérica, debía evitar la transferencia de indígenas para tierras localizadas afuera del área en que tradicionalmente deambulaban. Sin embargo, esta concesión tenía límite: sem, entretanto sacrificar as condições que possam concorrer para apressar a civilização e prosperidade deles ${ }^{11^{*}}$. $\mathrm{Si}$ los intereses ancestrales del territorio indígena eran armonizados con los exigidos por el SPI (carreteras, navegaciones y tierras fértiles) estaban consolidadas las primeras bases del contacto.

Al vislumbrar el panorama de los puestos y aldeas, vemos el montaje, las planificaciones/cartografías y también las desconexiones de esas instituciones, ya sea por falta de subsidio debido a la quiebra de la empresa, o simplemente por la diseminación de los grupos étnicos que estaban reducidos (epidemias, huidas, motines, conflictos...) o inclusive en algunos casos de mudanza de lugar, o por fusión de puestos debido a la reducida población. En un documento de marzo de 1919, dirigido al ministro de Agricultu$\mathrm{ra}$, solicitando visitas asiduas a los puestos y también reclamando sobre las dificultades de transportes en la Inspectoría del Servicio en el Estado de Mato Grosso y sobre la falta de recursos, el inspector apunta la acentuada indecisión administrativa en relación a la población indígena de São Lourenço, presentada por él como:

Importante estabelecimento agrícola em que se abrigam perto de 700 índios bororos, plantações de cereais, cana e mandioca cobrindo uma área total de 55 hectares, $e$ em que existem incalculáveis riquezas florestais a explorar, nota-se uma acentuada indecisão administrativa: nenhuma das obras iniciadas de 1911 a 1913 teve continuação; maquinismos para beneficiamento de cereais e cana de açúcar, ainda jazem nos depósitos, desmontadas; as plantações não se alargaram, nem melhoraram, os índios não tiveram melhoria de habitações, nem, portanto, os correlatos progressos nos hábitos e modos de vida ${ }^{12^{*}}$

En otro oficio de mayo de 1915, bastante anterior al recién citado, la misma población ya se encontraba con "problemas en su administración". En este caso, el encargado contaba con mano de obra indígena Bororo para los trabajos en el campo, lo que no fue viabilizado "por ser en ese momento la época de sus grandes cazas". Una hipótesis que puede ser vehiculada para explicar "la falta de administración", relatada por el inspector de Mato Grosso, en el año de 1919, es, en verdad, la no incorporación de los indígenas al modo de vida occidental, transformando sus actos, incluso dentro de los poblados, en un espacio sociocultural propio. Este hecho nos ayuda a pensar las relaciones étnicas y de alteridad de cada grupo, inclusive dentro de las instituciones denominadas "Puestos" y "Poblamientos".

Las características de las poblaciones indígenas, en el caso la de São Lourenço, están presentes en el documento de orientación del SPI para la Inspectoría, el cual contiene las instrucciones para su debida instalación, considerando las siguientes secciones: agricultura, zootecnia e industrias rurales. Sobre la estructura, la sede debía contar con:

parte urbana ou sede, escola primária, ferraria e carpintaria, depósito de máquinas e utensílios agrícolas, campo de experiência e demonstração, horta, jardim e po-

11 Instrucciones al Inspector en el Estado de Mato Grosso regulando los estudios para la fundación de una población indígena. Microfilme 380, fotograma 1217. Museo del Indio/FUNAI-RJ.

* $\quad$ sin, no obstante, sacrificar las condiciones que puedan ayudar para apresurar la civilización y la prosperidad de ellos.

12 Documento al ministro de Agricultura. Museo del Indio - Río de Janeiro. Microfilme 380, fotograma 1605.

* "un importante establecimiento agrícola en el que se abrigan cerca de 700 indios Bororos, plantaciones de cereales, caña y mandioca cubriendo un área total de 55 hectáreas, y en la cual existen incalculables riquezas forestales sin explorar, se nota una acentuada indecisión administrativa: ninguna de las obras iniciadas entre 1911 y 1913 tuvo continuidad; maquinarias dispuestas para el aprovechamiento de cereales y caña de azúcar aún están en los galpones, desmontadas; las plantaciones no aumentan, ni mejoran, los indios no mejoraron sus viviendas, ni, por lo tanto, los análogos progresos en los hábitos y modos de vida". 
mar, instalação para criação de animais, instalação para apicultura e avicultura etc $^{13^{*}}$

Al acompañar la trayectoria de este poblado en la documentación, es posible verificar que en 1943 fue "rebajada" para el estatus de PIN São Lourenço y al año siguiente, en 1944, no figura en la lista de puestos del SPI de Mato Grosso. ¿Que aconteció con este $y$ con otros puestos que fueron desactivados en el período en cuestión? A esta pregunta pretendo responder confrontando el ejemplo del Puesto Fraternidad Indígena, en Barra do Bugres, analizado en mi trabajo de Maestría (Arruda, 2003), en el cual verificamos la fusión de grupos indígenas en otro puesto mejor estructurado, durante lo que el propio órgano indigenista denominó como Colapso del SPI, entre 1930 y 1937, en que los subsidios fueron disminuidos, faltando dinero para la manutención de los puestos y para los reclutamientos, debiendo ser considerado, asimismo, el rechazo de tales proyectos por parte de los grupos indígenas.

Otra cuestión que necesita ser respondida es quiénes eran, a fin de cuentas, los grupos indígenas presentes en los puestos de atracción y pacificación. A partir de la localización de los puestos, vemos las etnias constituidas, y podemos cuantificarlas, nombrarlas e identificar prácticas dentro del universo simbólico de estos grupos y un movimiento de resignificación identitaria. Un documento de 1920 apunta esto de manera más evidente:

A Inspetoria estendeu muito o seu campo de ação, está em relação estreita com numerosos grupos de índios das tribos Bororos, Terenas, Quiniquinaus, Cayuás, Guaranys, Parecis, Cabixis, Bacahirys, Cadiuéos e Guatós. Quanto à estatística das responsáveis populações, não dispõe a Diretoria neste momento de elementos exatos, visto não ter sido ainda possível ao Inspetor remeter o seu relatório. Contudo, a Diretoria pode afirmar que só no Bananal há uma população avaliada em 800 índios Terenas; que os Cayoás e Guaranys, do Brilhante, Ivinheima, etc. são calculados em 10.000; que os Quiniquinaus aldeiados em Miranda, são mais do que 300; que os Bororo do Tarigara, de São Lourenço e do Quedjara, em relações contínuas e ininterruptas com a Inspetoria, sobem a mais de 700 , sendo a população total do rio São Lourenço ou rio Vermelho, avaliada em perto de 5000 almas; que os Parecys dos Postos do Utiarity e de Ponte de Pedra, são em número de 200. Quanto aos Cabixis, os Barbados e os Bacahirys não há ainda elementos para estimativa nenhuma... (...) Se a estas nações juntarmos os Nambikuaras, Kepiri-Uats, e numerosas outras encontradas e pacificadas pelo $\mathrm{Sr}$. General Rondon no sertão por ele aberto à civilização no noroeste mato-grossense, não estaremos muito longe da realidade computando em mais 20 tribos $^{14^{*}}$

En el período estudiado, algunos grupos sobresalen por las empresas de los frentes de expansión como en el caso de los Bororo, en el río São Lourenço, donde hoy se sitúa la ciudad de Rondonópolis, región sur de Mato Grosso. En la documentación, ellos son identificados también en Jarudore (puesto indígena que a lo

13 Documento al ministro de Agricultura. Museo del Indio - Río de Janeiro. Microfilme 380, fotograma 1605.

"parte urbana o sede, escuela primaria, herrería y carpintería, depósito de máquinas y utensilios agrícolas, campo de experimentación y demostración, huerta, jardín y plantaciones frutales, instalación para crianza de animales, instalación para apicultura e avicultura etc.".

14 Informes de las 6 Inspectorías del SPI, en 1920. Microfilme 380. Fotograma 1233, Museo del Indio/FUNAI-RJ.

* "La Inspectora extendió mucho su campo de acción, está en estrecha relación con numerosos grupos de indios de las tribus Bororos, Terenas, Quiniquinaus, Cayuás, Guaranys, Parecis, Cabixis, Bacahirys, Cadiuéos e Guatós. En lo relativo a las estadísticas de las poblaciones a su cargo, la Directoría no dispone en este momento de datos exactos, debido a que no le ha sido posible al inspector enviar su informe. No obstante, la Directoría puede afirmar que solo en el Bananal hay una población estimada de 800 indios Terenas; que los Cayoás y Guaranys, de los ríos Brilhante, Ivinheima, etc., son calculados en 10.000; que los Quiniquinaus conformados en aldeas en Miranda, son maás de 300; que los Bororo de Tarigara, de São Lourenço y de Quedjara, en relaciones continuas e interrumpidas con la Inspectoría suben a más de 700, siendo la población total del río São Lourenço o río Vermelho, calculada en cerca de 5000 almas; que los Parecys de los Puestos de Utiarity y del puente de la Pedra, existen en un número de 200. En cuanto a los Cabixis, los Barbados y los Bacahirys no hay aún elementos para ninguna estimación... (...) Si a estas naciones juntamos a los Nambikuaras, Kepiri-Uats, y numerosas otras encontradas y pacificadas por el Sr. General Rondon en el sertão abierto por él a la civilización en el noroeste matogrosense, no estaremos muy lejos de la realidad cuando calculamos más de 20 tribus". 
largo de la documentación desaparece y que hoy es un distrito del municipio de Poxoréo). Los Bororo estaban también en los márgenes de Río Poxoréo y en la ciudad de Guiratinga. Esas espacialidades, que hoy son ciudades, recibieron una gran cantidad de inmigrantes, oriundos del nordeste de Brasil, quienes llegaron a faenar en las minas de diamantes.

Otros grupos pueden ser evidenciados a partir de la investigación de esos documentos históricos. El nombramiento y demarcación de esos territorios dan visibilidad a aspectos obliterados por la historiografía contemporánea, como el hecho de no considerar las territorialidades indígenas en la historia de las ciudades que fueron construidas en aquellos espacios, concibiéndose el "mito de origen" ligado a la figura de los colonizadores. Los pueblos indígenas que todavía están localizados en las reservas, dentro de los límites de esos municipios, son todavía vistos, en su mayor parte, como estorbo para el progreso de las localidades. La coyuntura actual demuestra que hay una inversión de valores, no reconociendo a estos grupos étnicos en la historia de esos espacios, como si ellos estuviesen ahí localizados por una dádiva del Estado.

Deseamos nombrar otros personajes de estas relaciones sociales. Nos interesa saber sobre los agentes del SPI, en especial, de los encargados de los puestos, que fueron los responsables de la redacción de informes, cartas y telegramas que tenían la finalidad de registrar las transformaciones en los espacios administrados. En estas escrituras es posible constatar las relaciones con los frentes de expansión, informando los conflictos, enfrentamientos, comercio, entre otras relaciones. Los discursos y noticias producidas sobre estas espacializaciones, de cierta manera ayudaron a cristalizar los clichés de la emergente república. Para dar un ejemplo de cómo el discurso producido por los agentes fue reproducido, describiendo elementos para la construcción del pensamiento "na- cional" y de la concepción sobre el indígena, transcribo un trecho de un informe de 1926, dirigido al gobierno interventor del Estado de Mato Grosso, Mario Correa da Costa.

Entre os elementos que devem ser levados em conta, na diminuta população mattogrossense, como ponto de partida para o seu inevitável progresso, em que pese ao preconceito de muitos patrícios nossos, figuram também os índios. Raça boa, inteligente e forte, que trouxe desde o início da nacionalidade, ao nosso povo nascente, as qualidades admiráveis que a conquista do sertão brasileiro e a luta contra os invasores puseram na maior evidência, não pode ser votada ao extermínio, pelo assassinato, vício ou abandono ${ }^{15^{*}}$.

Entre los agentes es interesante identificar la presencia de los propios indígenas actuando como funcionarios del SPI, lo que sin duda sirvió como una estrategia de la atracción. En el trabajo de maestría antes citado (Arruda, 2003), cuando analizamos el Puesto Fraternidad Indígena, construido para la etnia Umutina, encontramos en la documentación la presencia de dos indios Bororo que actuaron como agentes del SPI y mediaron en el proceso de contacto. En este escenario, tanto estos personajes como los propios pueblos indígenas son importantes para problematizar las teorías sobre las relaciones de contacto.

Al tomar conocimiento de la documentación, son perceptibles, de antemano, acciones dentro de los puestos que fueron entendidas como patrones que debían ser seguidos. Es importante poner atención a la redacción de estos actos para percibir cómo las transformaciones, a los ojos de los agentes, fueron aconteciendo. Pese a las distinciones étnicoculturales presentes en los puestos, existió un verdadero "manual de contacto", montado y divulgado por el SPI. Para dar continuidad a este estudio dispongo de las fuentes documen-

15 Informe del Inspector interino Antonio Estigarríbia al gobernador del Estado de Mato Grosso sobre las acciones del SPI en los puestos localizados en el estado. Documento de 31 de mayo de 1926, de la Inspectoría de Mato Grosso. Carpeta Ministerios - Archivo Público de Mato Grosso.

* $\quad$ "Entre los elementos que deben ser tomados en cuenta, en la diminuta población matogrosense, como punto de partida para su inevitable progreso, en que pese al prejuicio de muchos compatriotas nuestros, figuran también los indios. Raza buena, inteligente y fuerte, que trajo desde el inicio de la nación, a nuestro pueblo naciente, las cualidades admirables que la conquista del sertão brasilero y la lucha contra los invasores pusieron en la mayor evidencia, no puede ser aniquilada, por el asesinato, el vicio o el abandono". 
tales del Servicio de Protección a los Indios ${ }^{16}$ y también del Archivo Histórico Clara Galvão - Coordinación General de Documentación de la FUNAI (Distrito Federal); otros documentos se encuentran en el Archivo Público del Estado de Mato Grosso.

El análisis del discurso presente en esta documentación es otro punto que hay que considerar en la investigación de los procesos de expansión. Es posible demostrar cómo es construida la concepción occidental del Otro, en la que el indígena es considerado cómo una "raza inferior", y caracterizado por los agentes como incapaz, salvaje, bárbaro, hostil, huraño y otros adjetivos que demostraban la inferioridad en relación al blanco civilizado ${ }^{17}$. Ese discurso estaba presente en los informes e instrucciones, como este de 1930, al esclarecer la diferencia del "indio" en relación al "caboclo". Según el SPI, después de que el "silvícola" fuese trabajado por los "legionarios de la pacificación" se transformaría en caboclo. Luego para el SPI:

"O índio é autóctone legítimo dos primitivos povoadores das nossas matas, insulado pela ignorância na selva selvagem, confundido com as feras, de que herdou a braveza. Inculto, na lata da expressão do termo, selvagem mesmo, relativamente refratário à higiene, falando dialeto próprio e especial, vivem uma brutalizada e com latente mentalidade guerreira" ${ }^{*}$.

Para comprender las acciones de los agentes en los puestos de atracción es necesario articular lo local -Mato Grosso (Brasil), limitado a los territorios que dieron la existencia a estos puestos- a las políticas generales del órgano cuya responsabilidad era dirigir los asuntos indígenas, teniendo como órgano mediador la Inspectoría Regional 06, localizada en la capital mato-grossense, en Cuiabá.
De esta manera, al reducir el foco de análisis para percibir las relaciones micro en los espacios de los puestos y, concomitantemente, al ampliarlo, para percibir las normativas del órgano estatal, vamos avanzando hacia una lectura donde es posible aprehender los múltiples contextos conjugados en las tramas socio-culturales de los puestos creados por el SPI y su entorno, posibilitándonos, así, comprender una historia social, que permite caracterizar a cada uno de los agentes históricos, con sus singularidades. Con esto en mente buscamos distanciarnos de un abordaje homogeneizante y pasivo, intentando visualizar, más allá de la cuestión de la identidad, las multiplicidades de acciones presentes en ese contexto, caracterizadas, igualmente, por la visión iluminista en la que la nación solo podría ser sólida y unificada a partir de un consenso cultural, esto es, de una cohesión nacional de normas válidas para toda la comunidad política. Este punto me hace recordar el trabajo de Clifford Geertz, en su artículo "Los Usos de la Diversidad", en el cual discute el futuro del etnocentrismo, poniendo en evidencia cómo una sociedad al presentarse nacional "cultiva oídos sordos para las diferencias, mostrándose sorda a la invocación de otros valores". Con una práctica semejante a la mencionada por el autor, la sociedad brasilera impidió el descubrimiento de la convivencia con el otro que era diferente y, al mismo tiempo, dejó de percibir que ese otro proporcionaba respuestas sobre el yo, el brasilero. Geertz propone que son las asimetrías entre lo que nosotros creemos o sentimos y lo que los otros creen y sienten, lo que permite localizar nuestro lugar en el mundo, cuál es la sensación de estar ahí, y dónde podemos querer o no querer ir. Nublar esas diferencias y esas asimetrías, relegándolas al campo de las diferencias plausibles de ser reprimidas o ignoradas, clasificadas como mera desigualdad -que es lo que el etnocentrismo hace y está programado para hacer-,

16 En relación a los puestos de atracción constan documentos como informes, instrucciones, cartas, oficios, telegramas, que están en el acervo del Museo del Indio (Río de Janeiro).

17 Para tal incursión, pretendo utilizar autores que se sumergen en esa discusión al final del siglo XIX e inicio del XX, como Lewis Morgan "La sociedad primitiva”; Lilia Moritz Schwarcz "O Espetáculo das Raças: cientístas, instituições e questão racial no Brasil"; Thomas Skidmore "Preto no Branco. Raça e nacionalidade no pensamento brasileiro".

18 Documento del Servicio de Protección al Indio, en 1930/31. Museo del Indio, Río de Janeiro. Microfilme 380. Fotograma 1267.

* "El indio es autóctono legítimo de los primitivos pobladores de nuestros bosques, aislado por la ignorancia en la selva salvaje, confundido con las fieras, de las que heredó la bravura. Inculto, en la exactitud de la palabra, claramente salvaje, relativamente resistente a la higiene, hablando su dialecto propio y especial, viven con una brutalizada y latente mentalidad guerrera". 
significa aislar la posibilidad de cambiar, en el más amplio y literal de los sentidos, nuestra mentalidad (Geertz, 1990, 24).

Sin embargo, el disciplinamiento del espacio no fue sinónimo de transformación del indígena en trabajador nacional, como los agentes y etnólogos del SPI relataban, ni menos aún significó la pérdida total de su identidad étnica. Esos puestos indígenas, sobre todo a partir de la década de 1980 , fueron rebautizados como reservas indígenas, prevaleciendo en el nombre de la reserva la designación de la etnia o de los nombres representativos de los grupos indígenas presentes en esas territorialidades. Muchos grupos reanudaron el proceso de revitalización cultural y social buscando la recreación de sus identidades, demostrando que las acciones del SPI y, posteriormente, de la FUNA ${ }^{19}$ en la década de 1970, fueron insuficientes para borrar la memoria sociocultural de esas etnias.

\section{Bibliografía}

ALMEIDA, M. (2003), “Metamorfoses indígenas: Identidades e cultura nas aldeias coloniais do Río de Janeiro". Río de Janeiro: Arquivo $\mathrm{Na}$ cional, Brasil.

AMOROSO, M. (2002), "Conquista do Paladar. Os Índios, o Império e as Promessas da Vida Eterna". Comunicação apresentada no Seminário FUNARTE "Brasil 500 Anos. Experiência e Destino, Nação e Região”. Brasil.

ARRUDA, L. (2003), “Posto Fraternidade Indígena: Estratégias de Civilização e Táticas de Resistência 1913 - 1945. Dissertação de Mestrado em História Social, Mato Grosso, UFMT, Brasil.

CABRAL, O. (1963), “Histórias de uma região
- Mato Grosso, fronteira Brasil-Bolívia e Rondônia". Rio de Janeiro, Brasil.

DIEHL, A. (1998), "A Cultura Historiográfica Brasileira. Do IHGB aos anos 1930". Passo Fundo, Ediupf, Brasil.

FOUCAULT, M. (1999), "Vigiar e Punir - Nascimento da Prisão". Petrópolis: Editora Vozes. $20^{a}$ edição, Brasil.

GALETTI, L. (2000), “Nos confins da civilização: sertão, fronteira e identidade nas representações sobre Mato Grosso". Tese de Doutorado em História Social, São Paulo, USP, Brasil.

GEERTZ, C. (1999), “Os Usos da Diversidade”. Revista Horizontes Antropológicos, n.10:1334. 1999.

LENHARO, A. (1986), “Colonização e Trabalho no Brasil: Amazônia, Nordeste e Centro-Oeste. Os anos 30". 2a Ed. Campinas: Papirus/Ed. Unicamp, Brasil.

LIMA, A. (1995), “Um Grande Cerco de Paz, Poder de Tutela, Indianidade e formação do estado no Brasil”. RJ, Ed. Vozes, Brasil.

MATTOS, I. (2003), "Civilização e Revolta - Os Botocudos e a Catequese na Província de Minas". EDUSC, Brasil.

OLIVEIRA, J. (1998), "Redimensionando a Questão Indígena no Brasil: Uma Etnografia das Terras Indígenas". Oliveira, J. P. (Org.), In: "Indigenismo e territorialização poderes, rotinas e saberes coloniais no Brasil contemporâneo". Rio de Janeiro, Contra Capa, Brasil.

THOMPSON, E. P. Miséria da teoria. Rio de Janeiro: Zahar, 1981.

A formação da classe operária inglesa. Rio de Janeiro: Paz e Terra, 1987. v. 1

19 La FUNAI -Fundación Nacional del Indio- fue creada por medio de la Ley en el № 5.371, de 5/12/1967, en sustitución al entonces recién extinto Servicio de Protección a los Indios (SPI). Es el organismo del gobierno brasileño que aplica la política indigenista oficial hasta el día de hoy, dando cumplimiento a lo que está determinado por la legislación del país. 